\title{
ANALISIS FAKTOR FAKTOR YANG MEMENGARUHI AKSEPTOR KB PRIA DI KECAMATAN SALEMBARAN JAYA KABUPATEN TANGERANG PROPINSI BANTEN TAHUN 2017
}

\author{
Dina Raidanti ${ }^{1}$ \\ ${ }^{1}$ Tenaga Pengajar Prodi D-III Kebidanan Akademi Kebidanan Assyifa Tangerang \\ Email :draidanti@gmail.com
}

\begin{abstract}
ABSTRAK
Partisipasi pria menjadi akseptor $\mathrm{KB}$ masih relatif kecil yaitu dengan target nasional 4,5\%. Penggunaan KB pada pria sampai dengan Oktober 2010 baru mencapai 4100 orang peserta dengan rincian yaitu kondom $(1,86 \%)$ dan MOP $(0,1 \%)$, tingkat pencapaian partisipasi pria ber KB masih relative rendah. Penelitian ini berupaya mengkaji faktor-faktor yang memengaruhi pria menjadi akseptor KB di wilayah Kecamatan Salembaran Jaya Kabupaten Tangerang tahun 2017.

Penelitian survei analitik dengan rancangan penelitian case control. Populasi dalam penelitian ini adalah seluruh pria pasangan usia subur yang menggunakan kontrasepsi dan tidak menggunakan, dalam penelitian ini sampel sebanyak 99 orang. Hasil Penelitian menunjukan bahwa Variabel usia, pendidikan dan dukungan TOGA adalah variabel yang memengaruhi akseptor KB pria.Variabel penghasilan, jumlah anak, pengetahuan dan dukungan isteri merupakan variabel confonding terhadap akseptor KB pria. Tidak ditemukan hubungan atau pengaruh antara akses pelayanan KB dan media informasi terhadap akseptor pria dalam KB.

Ditemukan bahwa Dukungan Tokoh Agama merupakan faktor dominan berhubungan dengan akseptor KB yang memiliki OR 9,852, Pria dengan dukungan Tokoh Agama yang baik memiliki peluang 9 kali untuk menjadi akseptor Keluarga Berencana.
\end{abstract}

Kata Kunci : Faktor-faktor KB Pria

\section{PENDAHULUAN}

Negara Indonesia merupakan negara terbesar penduduknya di dunia setelah Cina, India dan Amerika Serikat. Peningkatan persentase penduduk pada tahun 2050 berada di Afrika, yang populasinya diperkirakan dua kali lipat menjadi 2,1 miliar (Bandar S, 2000). Berdasarkan hasil sensus penduduk tahun 2000 jumlah penduduk Indonesia di perkirakan sebanyak 203 juta jiwa dan diperkirakan tahun 2050 sebanyak 315 juta jiwa. Sejalan dengan perubahan paradigma kependudukan dan pembangunan program Keluarga Berencana (KB) di Indonesia juga mengalami perubahan orientasi sesuai dengan kesepakatan bersama pada The International Conference on Population and Development (ICPD) pada tahun 1994 di Kairo, menjadi nuansa kesehatan reproduksi yang di dalamnya terkandung pengertian bahwa KB adalah suatu program yang dimaksudkan untuk membantu pasangan atau perorangan dalam mencapai tujuan reproduksinya (Sri Madya, 2009). Dengan adanya perubahan-perubahan tersebut program KB memerlukan adanya reorientasi dan reposisi program secara menyeluruh dan terpadu.

Prinsip pokok dalam mewujudkan keberhasilan program $\mathrm{KB}$ tersebut adalah peningkatan pemberdayaan perempuan serta peningkatan partisipasi pria dalam $\mathrm{KB}$ yang pada akhirnya dapat membantu untuk mewujudkan keluarga yang berkualitas dan 
sejahtera (BKKBN, 1989). Saat ini, 17\% pria menikah di Afrika sub-Sahara Afrika menggunakan bentuk modern keluarga berencana, sejauh ini tingkat terendah di dunia. (Bremer, Jason ;Frost, Ashley, Karin ; et al 2010). Di Amerika pasangan usia subur menggunakan metode KB sterilisasi (perempuan atau laki-laki) adalah metode yang disukai sebanyak (39\%) di ikuti dengan pil KB (27\%) dan kondom (20\%).

Hambatan lain termasuk kurangnya minat antara penyedia pelayanan kesehatan dalam menawarkan jasa dan jenis alat kontrasepsi untuk pria, kurangnya pelatihan, atau perhatian pelayanan bagi pria (Radita, 2008). Cakupan pria ber KB di negara Cina $8 \%$, India $7 \%$, Malaysia $16 \%$, Iran 13\%, Bangladesh 14\%, Korea 11\%, Srilangka 5\%, Thailand 6\%, Australia 10 $\%$, Selandia Baru 23\%, Inggris 12\%, Amerika 35\% dan Jepang 80\% (WHO, 2000). Hasil studi yang dilakukan oleh Puslitbang Biomedis dan Reproduksi Manusia pada tahun 1999 di DKI Jakarta dan DIY mengungkap bahwa rendahnya peran pria dalam ber-KB disebabkan karena kurangnya informasi tentang metode $\mathrm{KB}$ pria, terbatasnya jenis kontrasepsi pria, dan terbatasnya tempat pelayanan KB pria. Studi di Jawa Barat dan Sumatera Selatan tahun 2001 juga mengungkap penyebab rendahnya pria berKB sebagian besar disebabkan oleh faktor keluarga, yaitu isteri tidak mendukung (66\%), adanya rumor di masyarakat (47\%) kurangnya informasi metode pria, dan terbatasnya tempat pelayanan $(6,2 \%)$ (Hariastuti, Iswari, 2009).

Studi operasional yang dilakukan di DIY tahun 2000 menemukan bahwa sembilan dari sepuluh Pasangan Usia Subur beranggapan sterilisasi pria sama dengan dikebiri dan istri merasa takut suami berselingkuh bagi sebagian pria dinilai aneh dan asing, jadi tidak ada alasan untuk pria ber $\mathrm{KB}$, akibatnya tidak banyak pria yang menggunakan KB. Peserta KB pria terhadap total PUS berdasarkan hasil SDKI tahun 2007 baru mencapai 2,5\% di bandingkan sasaran Rencana Pembanguan
Jangka Menengah Nasional (RPJMN) pada tahun 2004 - 2009, yaitu sebesar 4,5\%. Kesertaan pria dalam ber KB masih sulit ditingkatkan, karena masih terbatasnya jenis alat $\mathrm{KB}$ pria dan masih kuatnya budaya patriarki (PP Presiden tentang RPJMN tahun 2010 - 2014). Selain itu masih menganggap pria adalah penguasa dan sebagai kepala keluarga adanya faktor nilai, persepsi masyarakat tentang $\mathrm{KB}$, budaya, pandangan agama dan dukungan isteri (Saptono, 2009). Masih ada nilai sosial negatif yang berhubungan dengan partisipasi pria ber $\mathrm{KB}$, selain itu tenaga kesehatan kurang sosialisasi ke masyarakat seperti kondom dan vasektomi kurang populer di masyarakat tentang manfaatnya dan adanya anggapan vasektomi dapat menurunkan libido.

Pada beberapa studi menunjukkan pengetahuan kontrasepsi yang tinggi namun penggunannya rendah. Penggunaan bervariasi di seluruh budaya dan dengan status ekonomi, umur, pendidikan, tempat tinggal (pedesaan/perkotaan), paparan layanan konseling, kepercayaan agama, informasi mengenai kontrasepsi, nilai anak laki-laki, komunikasi pasangan, ketersediaan dan pendidikan tentang penggunaan kondom, dan persepsi mereka tentang manfaat dari ukuran keluarga kecil adalah beberapa faktor yang mempengaruhi pengetahuan pria, dukungan untuk penggunaan kontrasepsi (Saptono, 2009). Menurut BKKBN Provinsi Banten, sampai dengan bulan Oktober 2008, prosentase penggunaan alat kontrasepsi untuk peserta $\mathrm{KB}$ baru (PB) tertinggi pada suntikan yaitu $55,63 \%$, sedangkan terendah pada penggunaan alat kontrasepsi untuk MOP $0,10 \%$. Pencapaian peserta baru KB pria sampai dengan bulan Oktober 2008 prosentase untuk mix kontrasepsi (MOP dan kondom) untuk kondom sebanyak 95,1\%, dan MOP sebanyak 4,48\%.

Partisipasi pria dalam keluarga berencana nasional maupun regional masih relatif kecil yaitu dengan target nasional $4,5 \%$. Penggunaan KB pada pria sampai dengan Oktober 2010 sebanyak 4100, 
peserta dengan rincian yaitu kondom $(1,86 \%)$ dan MOP $(0,1 \%)$, maka tingkat pencapaian partisipasi pria ber $\mathrm{KB}$ masih relative rendah. Hal ini mencerminkan kurangnya pemahaman pria terhadap $\mathrm{KB}$ dan hanya menyerahkan kepada perempuan. Oleh karena itu pentingnya kepesertaan pria dalam menggunakan $\mathrm{KB}$ akan berdampak pada peningkatan kesetaraan dalam tanggung jawab khususnya dalam kesehatan reproduksi dan meningkatkan kualitas hidup bangsa. Berdasarkan data laporan Puskesmas dan studi pendahuluan di Kecamatan Salembaran Jaya Kabupaten Tangerang terdapat PUS sebanyak 11.057 dengan peserta KB MOP 33 orang dan MOW sebanyak 67 orang untuk jumlah peserta kondom tidak disediakan karena kondom hanya di fasilitasi untuk para Wanita Tuna Susila (WTS) di sekitar wilayah Puskesmas Salembaran Jaya.

Berkaitan dengan hal-hal yang telah dikemukakan di atas maka perlu adanya penelitian mengenai faktor-faktor yang mempengaruhi akseptor KB pria di wilayah Kecamatan Salembaran Jaya Kabupaten Tangerang pada tahun 2017. Oleh sebab itulah berdasarkan uraian diatas penulis merasa tertarik untuk melakukan penelitian tentang faktor-faktor yang memengaruhi keikutsertaan pria menjadi akseptor KB di wilayah Kecamatan Salembaran Jaya Kabupaten Tangerang termasuk menganalisa Faktor dominan apa saja yang memengaruhi penggunaan KB pada pria di wilayah Kecamatan Salembaran Jaya Kabupaten Tangerang sehingga dapat diketahui secara jelas faktor-faktor yang memengaruhi keikutsertaan pria untuk menjadi akseptor KB di wilayah Kecamatan Salembaran Jaya Kabupaten Tangerang tahun 2017.

\section{METODE PENELITIAN}

Penelitian ini merupakan survei analitik dengan rancangan penelitian case control. Karena penelitian ini akan melakukan observasi data antara pria yang menjadi akseptor KB sebagai kasus dengan pria yang istrinya menjadi akseptor $\mathrm{KB}$ sebagai kontrol yang diamati secara bersama-sama, dengan faktor-faktor yang berhubungan dengan akseptor $\mathrm{KB}$ pria dalam program Keluarga Berencana (Arikunto, 1998). Penelitian dilakukan di wilayah kerja Puskesmas Salembaran Jaya Kabupaten Tangerang. Adapun penentuan lokasi berdasarkan 5 desa yang terdiri atas: Desa Rawaburung, Desa Rawarengas, Desa Belimbing, Desa Salembaran Jaya dan Desa Salembaran Jati.

Populasi kasus dalam penelitian ini adalah seluruh pria pasangan usia subur yang menggunakan kontrasepsi sebagai populasi kasus dan sebagian pria pasangan usia subur yang tidak menggunakan kontrasepsi sebagai populasi kontrol yang istrinya ber KB. Sampel penelitian adalah seluruh pria pasangan usia subur yang berada di wilayah Salembaran Jaya yang menggunakan alat kontrasepsi pria sebagai kasus sebagian pria yang istrinya menggunakan $\mathrm{KB}$ sebagai kontrol dengan perhitungan dengan perbandingan antara kasus dan kontrol $1: 2$. Dari perhitungan besar sampel berdasarkan survey awal didapatkan besar sampel yang digunakan adalah 33 orang untuk kelompok kasus dan kelompok kontrol sebanyak 66 orang sehingga jumlah sampel seluruhnya sebesar 99 orang. Instrument utama Pengumpulan data kuantitatif adalah kuesioner terstruktur dengan pertanyaan tertutup. Analisis data dilakukan dengan analisis univariat,bivariat dan multivariat.

\section{HASIL DAN PEMBAHASAN}

\section{Analisis Univariat}

Gambaran usia akseptor KB di wilayah Puskesmas Salembaran Jaya Tahun 2017 yang menjadi akseptor KB sebanyak 33 orang $(33,3 \%)$ sebagai kasus, Untuk lebih jelasnya dapat dianalisa pada tabel berikut ini: 


\section{Tabel 1}

Distribusi Responden

Terhadap Faktor- Faktor yang mempengaruhi Akseptor KB pada Pria di Wilayah Puskesmas Salembaran Jaya Tahun 2017

\begin{tabular}{|c|c|c|c|c|}
\hline Variabel & $\begin{array}{c}\begin{array}{c}\text { Ikut KB } \\
\text { (Kasus) } \\
\mathbf{N}=\mathbf{3 3}\end{array} \\
\end{array}$ & $\begin{array}{c}\text { Prosentase } \\
\%\end{array}$ & $\begin{array}{c}\text { Tidak Ikut } \\
\text { (Kontrol) } \\
\text { N = 66 }\end{array}$ & $\begin{array}{c}\text { Prosentase } \\
\%\end{array}$ \\
\hline \multicolumn{5}{|l|}{ Usia } \\
\hline$\geq 31$ tahun & 31 & $94 \%$ & 47 & $71 \%$ \\
\hline$<31$ tahun & 2 & $6 \%$ & 19 & $29 \%$ \\
\hline \multicolumn{5}{|l|}{ Pendidikan } \\
\hline Lanjutan & 29 & $88 \%$ & 42 & $64 \%$ \\
\hline Dasar & 4 & $12 \%$ & 24 & $36 \%$ \\
\hline \multicolumn{5}{|l|}{ Jumlah Anak } \\
\hline Banyak & 21 & $64 \%$ & 24 & $36 \%$ \\
\hline Sedikit & 12 & $36 \%$ & 42 & $64 \%$ \\
\hline \multicolumn{5}{|l|}{ Penghasilan } \\
\hline$\geq$ Rp. 1.800 .000 & 20 & $61 \%$ & 37 & $56 \%$ \\
\hline < Rp. 1.800 .000 & 13 & $39 \%$ & 29 & $44 \%$ \\
\hline \multicolumn{5}{|c|}{ Dukungan TOGA } \\
\hline Baik & 29 & $88 \%$ & 43 & $65 \%$ \\
\hline Kurang & 4 & $12 \%$ & 23 & $35 \%$ \\
\hline \multicolumn{5}{|l|}{ Dukungan Istri } \\
\hline Baik & 17 & $52 \%$ & 48 & $73 \%$ \\
\hline Kurang & 16 & $48 \%$ & 18 & $27 \%$ \\
\hline \multicolumn{5}{|c|}{ Akses Media Informasi } \\
\hline Baik & 18 & $55 \%$ & 31 & $47 \%$ \\
\hline Kurang & 15 & $45 \%$ & 35 & $53 \%$ \\
\hline \multicolumn{5}{|l|}{ Pengetahuan } \\
\hline Baik & 12 & $36 \%$ & 40 & $61 \%$ \\
\hline Kurang & 21 & $64 \%$ & 26 & $39 \%$ \\
\hline \multicolumn{5}{|c|}{ Akses Pelayanan KB } \\
\hline Baik & 15 & $45 \%$ & 24 & $36 \%$ \\
\hline Kurang & 18 & $55 \%$ & 42 & $64 \%$ \\
\hline
\end{tabular}

Sumber : Data Primer Terolah

Berdasarkan Tabel 1 dapat terlihat dari sisi usia pria yang berusia $\geq 31$ tahun yang menjadi akseptor KB (kasus) sebanyak 31 orang $(94 \%)$, sedangkan pria yang tiak mengikuti KB (kontrol) sebanyak 47 orang (71\%. Berdasarkan pendidikan lanjutan yang menjadi akseptor KB (kasus) sebanyak 29 orang (88\%), sedangkan pria yang tidak mengikuti KB (kontrol) sebanyak 42 orang (64\%). Berdasarkan jumlah anak yang dimiliki anak banyak dan menjadi akseptor KB (kasus) sebanyak 21 orang $(64 \%)$, sedangkan pria yang memiliki anak banyak yang tidak mengikuti $\mathrm{KB}$ (kontrol) sebanyak 24 orang (36\%). Berdasarkan penghasilan pria yang berpenghasilan $\geq$ Rp. 1.800 .000 yang menjadi akseptor KB pada pria (kasus) sebanyak 20 orang $(61 \%)$ sedangkan pria sebagai (kontrol) sebanyak 37 orang $(56 \%)$.

Berdasarkan dukungan TOGA yang memiliki dukungan yang baik dan menjadi akseptor KB pada pria yang menjadi akseptor KB (kasus) sebanyak 29 orang (88\%), sedangkan pria yang (kontrol) sebanyak 43 orang (65\%). Berdasarkan dukungan isteri yang memiliki dukungan yang baik dan menjadi akseptor KB pada pria yang (kasus) sebanyak 17 orang (52\%), sedangkan pria sebagai (kontrol) sebanyak 48 orang $(73 \%)$. Berdasarkan akses media informasi memiliki akses yang baik dan menjadi akseptor KB pada pria yang (kasus) sebanyak 18 orang (55\%), sedangkan pria yang (kontrol) sebanyak 31 orang (47\%). Berdasarkan pengetahuan memiliki pengetahuan baik dan menjadi 
akseptor KB pada pria (kasus) sebanyak 12 orang $(36 \%)$, sedangkan pria sebagai (kontrol) sebanyak 40 orang $(61 \%)$. Berdasarkan akses pelayanan KB yang memiliki akses yang baik dan menjadi akseptor KB pada pria (kasus) sebanyak 15 orang $(45 \%)$, sedangkan pria yang (kontrol) sebanyak 24 orang $(36 \%)$.

\section{Analisis Bivariat}

Analisis Bivariat ditujukan untuk menganalisis hubungan antar variabel penelitian ini, untuk lebih jelasnya dapat dianalisis pada tabel berikut ini:

Tabel 2

Hubungan Faktor-Faktor yang memengaruhi Akseptor KB pada pria di Wilayah Puskesmas Salembaran Jaya Tahun 2017

\begin{tabular}{|c|c|c|c|c|c|c|}
\hline \multirow{3}{*}{ Variabel } & \multicolumn{4}{|c|}{ Akseptor KB Pria } & \multirow{3}{*}{ P value } & \multirow{3}{*}{ OR $(95 \% \mathrm{CI})$} \\
\hline & \multicolumn{2}{|c|}{ Ikut } & \multicolumn{2}{|c|}{ Tidak Ikut } & & \\
\hline & $\mathbf{N}$ & $\%$ & $\mathbf{N}$ & $\%$ & & \\
\hline \multicolumn{7}{|l|}{ Usia } \\
\hline$\geq 31$ tahun & 31 & 39,7 & 47 & 60,3 & \multirow[t]{2}{*}{0,019} & 6,266 \\
\hline$<31$ tahun & 2 & 9,5 & 19 & 90,5 & & $(1,362-28,821)$ \\
\hline \multicolumn{7}{|l|}{ Pendidikan } \\
\hline Lanjutan & 29 & 40,8 & 42 & 59,2 & \multirow{2}{*}{0,022} & 4,143 \\
\hline Dasar & 4 & 14,3 & 24 & 85,7 & & $(1,299-13,208)$ \\
\hline \multicolumn{7}{|l|}{ Penghasilan } \\
\hline$\geq$ Rp. 1.800 .000 & 20 & 35,1 & 37 & 64,9 & \multirow[t]{2}{*}{$\mathbf{0 , 8 2 9}$} & 1,206 \\
\hline < Rp. 1.800 .000 & 13 & 31,0 & 29 & 69,0 & & $(0,515-2,823)$ \\
\hline \multicolumn{7}{|l|}{ Jumlah Anak } \\
\hline Banyak & 21 & 46,7 & 24 & 53,3 & \multirow[t]{2}{*}{0,019} & 3,063 \\
\hline Sedikit & 12 & 22,2 & 42 & 77,8 & & $(1,285-7,300)$ \\
\hline \multicolumn{7}{|l|}{ Dukungan TOGA } \\
\hline Baik & 29 & 40,3 & 43 & 59,7 & \multirow{2}{*}{0,031} & 3,878 \\
\hline Kurang & 4 & 14,8 & 23 & 85,2 & & $(1,285-12,389)$ \\
\hline \multicolumn{7}{|l|}{ Dukungan Istri } \\
\hline Baik & 17 & 26,2 & 48 & 73,8 & \multirow{2}{*}{0,061} & 0,389 \\
\hline Kurang & 16 & 47,1 & 18 & 52,9 & & $(0,167-0,952)$ \\
\hline \multicolumn{7}{|c|}{ Akses Media Informasi } \\
\hline Baik & 18 & 36,7 & 31 & 63,6 & \multirow[t]{2}{*}{0,619} & 1,355 \\
\hline Kurang & 15 & 30,0 & 35 & 70,0 & & $(0,586-3,134)$ \\
\hline \multicolumn{7}{|l|}{ Pengetahuan } \\
\hline Baik & 12 & 23,1 & 40 & 76,9 & \multirow[t]{2}{*}{0,039} & 0,371 \\
\hline Kurang & 21 & 44,7 & 26 & 55,3 & & $(0,157-0881)$ \\
\hline \multicolumn{7}{|c|}{ Akses Pelayanan KB } \\
\hline Baik & 15 & 38,9 & 24 & 61,5 & \multirow{2}{*}{0,513} & 1,458 \\
\hline Kurang & 18 & 30,0 & 42 & 70,0 & & $(0,624-3,409)$ \\
\hline
\end{tabular}

Sumber : Data Primer Terolah

Berdasarkan Tabel 2 dapa dianalisis besaran hubungan dan pengaruh antar variabel yang dipaparkan seperti berikut ini. Hubungan antar usia dengan kejadian akseptor pria dalam $\mathrm{KB}$ pria yang berusia $\geq$ 31 tahun yang menjadi akseptor KB (kasus) sebanyak 31 orang $(39,7)$, dan pria berusia $<31$ tahun yang menjadi akseptor KB (kasus) sebanyak 2 orang $(9,5 \%)$. Berdasarkan hasil uji statistik hubungan antara usia dengan akseptor pria dalam $\mathrm{KB}$ didapatkan nilai $p$ value $=0,019$ yang berarti ada hubungan antara usia dengan akseptor pria dalam KB sedangkan OR 6,266 artinya pria yang berusia $\geq 31$ tahun memiliki peluang untuk menjadi akseptor 
KB sebanyak 6 kali dibandingkan dengan pria yang berusia $<31$ tahun.

Berdasarkan hubungan antara pendidikan dengan akseptor $\mathrm{KB}$ pria di peroleh hasil yaitu pria yang berpendidikan lanjutan yang menjadi akseptor KB (kasus) ada 29 orang $(40,8 \%)$ dan yang memiliki pendidikan dasar yang menjadi akseptor KB (kasus) sebanyak 4 orang (14,3\%). Berdasarkan hasil uji statistik hubungan antara pendidikan dengan akseptor pria dalam KB secara statistik didapatkan $p$ value $=0,022$ yang berarti ada hubungan antara pendidikan dengan akseptor pria dalam KB, sedangkan OR 4,143 berarti pria yang berpendidikan lanjutan mempunyai kemungkinan 4 kali memiliki peluang untuk menjadi akseptor dalam $\mathrm{KB}$ di bandingkan dengan pria yang memiliki Pendidikan Dasar.

Hasil penelitian hubungan antara penghasilan dengan akseptor pria dalam $\mathrm{KB}$ yang memiliki penghasilan $\geq \mathrm{Rp}$. 1.800 .000 dan menjadi akseptor KB (kasus) sebanyak 20 orang $(35,1 \%)$, sedangkan pria yang penghasilan < Rp. 1.800 .000 dan menjadi akseptor KB (kasus) sebanyak 13 orang (31,0\%). Hasil uji statistik hubungan antara penghasilan dengan akseptor pria dalam KB secara statistik didapatkan nilai $p$ value $=0,829$ yang berarti tidak ada hubungan antara penghasilan dengan akseptor pria dalam KB

Hasil penelitian hubungan antara jumlah anak dengan akseptor KB pria dalam KB yang memiliki banyak dan menjadi akseptor KB (kasus) sebanyak 21 orang $(46,7)$ sedangkan pria yang memiliki anak sedikit dan menjadi akseptor $\mathrm{KB}$ (kasus) sebanyak 12 orang (22,2\%). Hasil uji statistik hubungan antara jumlah anak dengan akseptor $\mathrm{KB}$ pria dalam KB secara statistik didapatkan $p$ value $=0,019$ yang berarti ada hubungan antara jumlah anak dengan akseptor pria dalam KB, sedangkan dari hasil analisis didapatkan $\mathrm{OR}=3,063$, artinya pria yang memiliki anak banyak memiliki peluang 3 kali lebih besar dibandingkan dengan pria yang anaknya sedikit.

Berdasarkan hubungan antara dukungan TOGA dengan akseptor pria dalam KB yang di dukung dalam menggunakan akseptor KB (kasus) sebanyak 29 orang (40,3\%), sedangkan pria yang kurang dukungan oleh TOGA untuk menjadi akseptor KB (kasus) sebanyak 4 orang $(14,8 \%)$. Dari 8 pertanyaan yang diajukan mengenai dukungan TOGA yaitu tentang bentuk legalitas dari segi agama, bentuk dukungan, serta bentuk penyuluhan yang diberikan didapatkan sebagian mengatakan tokoh agama mendukung baik tentang pengunaan akseptor Pria dalam KB namun sebagian responden yang mendapatkan dukungan TOGA yang baik tetapi tidak bersedia menjadi akseptor KB, hal ini juga dipengaruhi oleh entuk dukungan yang tidak secara aktif TOGA dalam membolehkan pria untuk ber KB hal ini didukung oleh tidak adanya penyuluhan secara aktif dari tenaga kesehatan yang di dampingi oleh TOGA termasuk penanganan komplikasi yang dibantu oleh TOGA. Hasi uji statistik hubungan antara dukungan TOGA dengan akseptor KB pria dalam KB secara statistik didapatkan nilai $p$ value $=0,031$ yang berarti ada hubungan antara dukungan TOGA dengan akseptor pria dalam $\mathrm{KB}$, sedangkan OR 3,878 berarti pria yang memiliki dukungan yang baik oleh TOGA mempunyai kemungkinan 3 kali peluang untuk menjadi akseptor KB. Di bandingkan dengan pria yang kurang didukung oleh TOGA.

Berdasarkan hubungan antara dukungan isteri dengan akseptor pria dalam KB yang didukung oleh isteri menggunakan akseptor KB (kasus) sebanyak 17 orang $(26,2 \%)$, sedangkan pria yang kurang di dukung oleh isteri untuk menjadi akseptor KB (kasus) sebanyak 16 
orang $(47,1 \%)$ dan yang tidak menjadi akseptor KB (kontrol) sebanyak 18 orang $(52,9 \%)$. Dari 10 pertanyaan yang diajukan mengenai dukungan isteri berupa alasan isteri mendukung pria menjadi akseptor $\mathrm{KB}$, sebagian responden didukung oleh isteri untuk ber $\mathrm{KB}$, namun responden tidak ber $\mathrm{KB}$ hal ini dapat dilihat dari faktor kesetaraan gender karena sebagian responden beranggapan bahwa KB adalah masih menjadi urusan isteri. Berdasarkan hasil uji statistik hubungan antara dukungan isteri dengan akseptor $\mathrm{KB}$ pria dalam KB seara statistik didapatkan nilai $p$ value $=0,061$ yang berarti tidak ada hubungan antara dukungan isteri dengan akseptor pria dalam $\mathrm{KB}$, sedangkan OR 0,398 berarti pria yang memiliki dukungan yang baik oleh isteri mempunyai kemungkinan 0,398 kali peluang untuk menjadi akseptor KB di bandingkan dengan pria yang kurang didukung oleh isteri.

Berdasarkan hubungan antara akses media informasi dengan akseptor pria dalam KB yang memiliki akses baik sehingga menjadi akseptor $\mathrm{KB}$ (kasus) sebanyak 18 orang $(36,7 \%)$, sedangkan pria yang kurang memiliki akses terhadap media informasi untuk menjadi akseptor KB (kasus) sebanyak 15 orang (30\%). Dari 4 pertanyaan yang diajukan tentang akses media informasi tentang $\mathrm{KB}$ mempunyai informasi tentang $\mathrm{KB}$, kemudahan akses, kejelasan informasi serta peran nakes dan media informasi didapatkan bahwa sebagian responden mengetahui baik tentang informasi $\mathrm{KB}$ namun responden yang tidak mengikuti $\mathrm{KB}$ memiliki informasi yang baik tentang $\mathrm{KB}$ tidak bersedia menjadi akseptor. Hal ini disebabkan oleh beberapa faktor karena informasi yang mereka dapatkan belum secara komperhenshif sehingga pengetahuan responden masih rendah. Berdasarkan hasil uji statistik hubungan antara akses terhadap media informasi dengan akseptor $\mathrm{KB}$ pria dalam $\mathrm{KB}$ secara statistik didapatkan nilai $\mathrm{p}$ value $=0,619$ yang berarti tidak ada hubungan antara akses terhadap media informasi dengan akseptor pria dalam KB.

Berdasarkan hubungan antara pengetahuan dengan akseptor Pria dalam KB yang memiliki pengetahuan baik (kasus) sebanyak 12 orang $(23,1 \%)$, dan yang tidak menjadi akseptor KB (kontrol) sebanyak 40 orang $(76,9 \%)$, sedangkan pria yang memiliki pengetahuan kurang (kasus) sebanyak 21 orang $(44,7 \%)$ dan yang tidak menjadi akseptor KB (kontrol) sebanyak 26 orang $(55,3 \%)$. Berdasarkan beberapa pertanyaan yang diajukan tentang pengetahuan $\mathrm{KB}$ pada pria yaitu tentang tujuan $\mathrm{KB}$, jenis $\mathrm{KB}$, efek samping serta tempat pelayanan $\mathrm{KB}$ sebagian responden memiliki pengetahuan rendah tentang tujuan $\mathrm{KB}$, jenis $\mathrm{KB}$, efek samping serta tempat pelayanan $\mathrm{KB}$ sehingga mempengaruhi pemahaman responden tentang $\mathrm{KB}$ pada pria. Hasil uji statistik hubungan antara pengetahuan dengan akseptor KB pria dalam KB secara statistik didapatkan nilai $\mathrm{p}$ value $=0,039$ yang berarti ada hubungan antara pengetahuan dengan akseptor pria dalam KB, sedangkan OR 0,157 berarti pria yang memiliki pengetahuan yang baik mempunyai kemungkinan 0,157 kali peluang untuk menjadi akseptor $\mathrm{KB}$ dibandingkan pria yang memiliki pengetahuan yang kurang.

Berdasarkan hubungan antara akses pelayanan $\mathrm{KB}$ dengan akseptor pria dalam KB yang memiliki akses baik (kasus) sebanyak 15 orang $(38,5 \%)$, sedangkan pria yang memiliki akses kurang (kasus) sebanyak 18 orang (30\%). Berdasarkan 11 pertanyaan yang diajukan tentang akses pelayanan $\mathrm{KB}$ pria sebagian responden tidak mendapatkan akses yang baik untuk mendapatkan pelayanan $\mathrm{KB}$ pria, hal ini karena masih rendahnya sosialisasi dari petugas pelayanan kesehatan tentang 
tempat pelayanan KB. Berdasarkan hasil uji statistik hubungan antara akses terhadap media informasi dengan akseptor KB pria dalam KB secara statistik didapatkan nilai

\section{Analisis Multivariat}

Langkah awal analisis multivariat ini adalah dengan melakukan Pemilihan kandidat variabel yang masuk dalam multivariat hal ini dilakukan melalui $p$ value $=0,513$ yang berarti tidak ada hubungan antara pengetahuan dengan akseptor pria dalam KB.

analisis terhadap masing-masing kovariat. Variabel yang masuk ke dalam model multivariat adalah variabel yang mempunyai nilai $p$ value $<0,25$.

Tabel 3

Hasil Analisa Masing-masing Kovariat Akseptor KB Pria Di Wilayah Puskesmas Salembaran Jaya Tahun 2017

\begin{tabular}{clcc}
\hline No & \multicolumn{1}{c}{ Variabel } & P value & Keterangan \\
\hline 1 & Penghasilan & 0,829 & Bukan Kandidat \\
2 & Akses media informasi & 0,619 & Bukan Kandidat \\
3 & Akses pelayanan KB & 0,513 & Bukan Kandidat \\
\hline
\end{tabular}

Sumber : Data Primer Terolah

Variabel dengan $p$ value $>0,25$ dikeluarkan karena tidak masuk dalam kandidat multivariate. Namun demikian variabel akses pelayanan $\mathrm{KB}$, media informasi dan penghasilan dianggap penting secara teori memiliki hubungan dengan akseptor $\mathrm{KB}$ pria dalam $\mathrm{KB}$ sehingga ketiga variabel tersebut dimasukkan ke dalam pemodelan untuk multivariat.

Analisa multivariate bertujuan untuk mendapatkan model terbaik dalam menentukan variabel yang dominan dalam akseptor pria dalam KB. Semua variabel yang menjadi kandidat multivariate ini dimasukan ke dalam pemodelan secara bersama-sama yang dilanjutkan dengan evaliasi hasil regresi logistik dengan melihat nilai $\mathrm{p}$ dengan melihat derajat kemaknaan 0,05 . Variabel yang mempunyai nilai $\mathrm{p}>0,05$ dikeluarkan dari pemodelan dengan pertimbangan melihat perubahan nilai OR sebelum dan sesudah dikeluarkan dari pemodelan. Apabila terdapat perubahan $\mathrm{OR}>10 \%$ maka variabel tersebut dimasukan kembali.

\section{Tabel 4}

Hasil Uji Regresi Logistik Tahap Akhir Antara Variabel

Usia, Pendidikan, Dukungan TOGA, Penghasilan, Jumlah Anak, Pengetahuan, dan Dukungan Isteri

\begin{tabular}{clcccc}
\hline \multirow{2}{*}{ No } & \multirow{2}{*}{ Variabel } & \multirow{2}{*}{ P value } & \multirow{2}{*}{ OR } & \multicolumn{2}{c}{ CI 95\% } \\
\cline { 5 - 6 } & & & Lower & Upper \\
\hline $\mathbf{1}$ & Usia & 0,040 & 7,625 & 1,097 & 52,993 \\
$\mathbf{2}$ & Pendidikan & 0,044 & 3,988 & 1,041 & 15,288 \\
$\mathbf{3}$ & Dukungan TOGA & 0,004 & $\mathbf{9 , 8 5 2}$ & 2,091 & 46,427 \\
4 & Penghasilan & 0,472 & 1,506 & 0,493 & 4,600 \\
5 & Jumlah Anak & 0,137 & 2,246 & 0,774 & 6,522 \\
6 & Pengetahuan & 0,096 & 0,348 & 0,100 & 1,205 \\
7 & Dukungan Isteri & 0,076 & 0,283 & 0,070 & 1,144 \\
\hline
\end{tabular}

Sumber : Data Primer Terolah 
Berdasarkan pemodelan terakhir maka ada 3 variabel yang mempengaruhi akseptor pria dalam KB (usia, pendidikan, dukungan TOGA), sedangkan variabel (dukungan isteri, pengetahuan, pengasilan dan jumlah anak) adalah sebagai variabel konfonding dalam memengaruhi akseptor pria dalam KB sehingga dilakukan uji interaksi. Uji interaksi dilakukan antar variabel usia dengan jumlah anak, pendidikan dengan pengetahuan, pendidikan dengan penghasilan karena di duga secara substansi ada intearksi antar dua variabel tersebut dengan akseptor KB pada pria.

Berdasarkan hasil perhitungan uji interaksi yang dilakukan maka didapatkan bahwa variabel usia by jumlah anak memiliki p value $>0,05$ (tidak berinteraksi) kemudian dikeluarkan, selanjutnya variabel pendidikan by penghasilan dan variabel pendidikan by pengetahuan variabel tersebut dikeluarkan sehingga diperoleh kesimpulan bahwa variabel tersebut tidak saling berinteraksi karena $\mathrm{p}$ value $>0,05$, maka variabel dukungan TOGA adalah variabel dominan yang memengaruhi akseptor pria dalam KB dengan 9,852 artinya pria yang memiliki dukungan TOGA memiliki peluang 10 kali untuk menjadi akseptor pria dalam $\mathrm{KB}$ setelah control oleh variabel usia, pendidikan dan penghasilan.

\section{KESIMPULAN}

Berdasarkan hasil penelitian dan pengamatan kemudian pembahasan dalam penelitian ini maka dapat diambil kesimpulan sebagai berikut :

1. Variabel usia, pendidikan dan dukungan TOGA adalah variabel yang memengaruhi terhadap akseptor $\mathrm{KB}$ pria.

2. Variabel penghasilan, jumlah anak, pengetahuan dan dukungan isteri adalah merupakan variabel confonding terhadap akseptor pria dalam KB.
3. Tidak ditemukan hubungan atau pengaruh antara akses pelayanan $\mathrm{KB}$ dan media informasi terhadap akseptor pria dalam KB di wilayah kerja Puskesmas Salembaran Jaya Kabupaten Tangerang.

4. Ditemukan bahwa Dukungan Tokoh Agama merupakan faktor dominan berhubungan dengan akseptor KB yang memiliki OR 9,852,

5. Pria dengan dukungan Tokoh Agama yang baik yang memiliki peluang $9 \mathrm{kali}$ untuk menjadi akseptor KB.

\section{SARAN}

1. Dinas Kesehatan Kabupaten Tangerang

a. Perlu adanya sosialisasi dengan tokoh agama tentang metode $\mathrm{KB}$ pada pria sehingga para TOGA dapat menjadi motivator bagi pria untuk menjadi akseptor KB.

b. Perlu adanya kerjasama lintas sektor dalam sosialisasi jenis alat kontrasepsi pada pria sehingga peran serta pria sebagai akseptor KB meningkat.

c. Mengadakan kerjasama dengan pihak terkait seperti BKKBN, pihak Puskesmas lebih proaktif dengan melibatkan unsur tokoh agama yang berasal dari masyarakat untuk mengadakan penyuluhan dan mendorong para TOGA untuk menjadi akseptor KB pria agar menjadi role, model bagi para warga masyarakat sekitar agar para pria bersedia untuk menjadi akseptor KB pria.

d. Mengadakan penyuluhan secara berkala guna meningkatkan pemahaman pria tentang jenis alkon pada pria.

2. Para pria Calon Akseptor KB untuk tidak sungkan menjadi Akseptor KB yang baik sebagai bentuk tanggung jawab laki-laki dalam membina rumah tangga dan keluarga yang bahagia. 
3. Puskesmas Salembaran Jaya Tangerang

a. Perlunya peningkatn KIE melalui paguyuban atau kelompok KB pria yang didukung oleh tokoh agama

\section{DAFTAR PUSTAKA}

Arikunto, S. (1998). Prosedur Penelitian: suatu Pendekatan Praktek. Jakarta: Rineka Cipta

Bandar, S. (2000). Peran Pria dalam KB Nasional. Jakarta: BKKBN.

BKKBN. (1989). Pengayoman Medis Keluarga Berencana. Dibuka pada http://www.bkkbn.bkkbn.go.id/pengay oman + medis $+K B \& h l=i d \& c t=c l n k \& c$ $\mathrm{d}=4 \& \mathrm{gl}=\mathrm{i}$

BKKBN. (1991). Materi Pelajaran Metode Kontrasepsi Efektif Terpilih. Dibuka pada http://prov.bkkbn.go.id/banten/print.p hp?tid=2\&rid=34

BKKBN. (1997). 25 tahun Gerakan KB. Dibuka pada http://pustaka.bkkbn.go.id/index.php? option=com_content\&task=view\&id= $109 \&$ Itemid $=9$

BKKBN. (1998). Opini Pembangunan Keluarga Sejahtera. Dibuka pada http://prov.bkkbn.go.id/bali/print.php? tid $=2 \&$ rid $=1$

BKKBN. (2004). Partisipasi Pria dalam Program KB masih rendah. Dibuka pada http://www.bkkbn.go.id/Webs/DetailR ubrik.aspx?MyID=2282

BKKBN. (2005). Kontrasepsi Baru Pria. Dibuka pada http://prov.bkkbn.go.id/gemapria/artic le-detail.php?artid=70

BKKBN. (2007). Kebijakan Program Pokok dan Kegiatan Bidang Pelayanan Keluarga Berencana dan Kesehatan Reproduksi. Dibuka pada http://www.bkkbn.go.id/Webs/DetailR ubrik.aspx? $\mathrm{MyID}=2282$ tentang alat kontrasepsi pria untuk meningkatkan pengetahuan pria tentang alat kontrasepsi.

b. Menjadikan TOGA sebagai kader agar mampu menjadi contoh bagi para pria untuk ber KB.
Brockopp, Dorothy Young \& Marie T. Hasting - Tolsma. (1999). Dasardasar Riset Keperawatan. Edisi 2. Jakarta: EGC

Ginting, Paham \& Syafrizal Helmi Situmorang. (2008). Filsafat Ilmu dan Metode Riset. Medan: USU Press

Hariastuti, Iswari. (2009). Peran Pria dalam Penggunaan Kontrasepsi di Jawa Timur. Dibuka pada http://www.tempointeraktif.com/hg/ke sehatan/2008/08/11/brk,20080811130344,id.html

Hartanto, Hanafi. (2003). Keluarga Berencana dan Kontrasepsi. Jakarta: Pustaka Sinar Harapan

Hestiantoro, Anton. (2008). Plus Minus Alat Kontrasepsi. Dibuka pada http://momsnbabies. wordpress.com/20 08/02/19/plus-minus-alat-kontrasepsi/

Universitas Sumatera Utara Joomla. (2009). Determinan Persepsi. Dibuka pada http://rumahbelajarpsikologi.com/inde x.php/pengaruhi-persepsi.html

Kesumaningtyas, A. (2008). PUS Medan Denai tak terjangkau KB. Dibuka pada http://www.waspada.co.id/index2.php ?option $=$ comcontent $\&$ do pdf=I\&id=32056

Komaruddin \& Komaruddin. (2000). Kamus Istilah Karya Tulis Ilmiah. Jakarta: Bumi Aksara.

Manuaba, I. B. G. (1998). Ilmu Kebidanan, Penyakit Kandungan dan Keluarga Berencana. Jakarta: EGC 
Mardalis. (1995). Metode penelitian :

Suatu pendekatan proposal. Jakarta:

Bumi Aksara.

Mochtar, R. (1998). Sinopsis Obstetri 2. Jakarta: EGC

Neufeldt, V \& Guralnik, D. B. (1996).

Webster's new world college

dictionary third edition. New York:

Macmillan.

Notoadmojo, S. (1993). Pengantar

Pendidikan Kesehatan dan Ilmu

Perilaku Kesehatan. Ed.1. .

Yogyakarta: Andi Offset

Prawirohardjo, Sarwono. (2002). Ilmu

Kebidanan. Jakarta Pusat: Tridasa Printer

Rahmat. (1992) dalam Jurnal Keperawatan

Rufaidah Fakultas Kedokteran

Universitas Sumatera Utara. Vol 1 (2005)

Setiadi. (2007). Konsep dan Penulisan

Riset Keperawatan. Yogyakarta:

Graha Ilmu

Siagian, P. S. (1995). Teori Motivasi dan

Aplikasinya. Jakarta: Rineka Cipta

Siswono. (2005). Pemakaian Alat

Kontrasepsi Masih Belum

Membudaya pada Pria. Dibuka pada

http://www.gizi.net/cgi-

bin/berita/fullnews.cgi?newsid111138 4658,57725,

Slameto. (2003). Belajar dan Faktorfaktor yang Mempengaruhinya. Jakarta: Rineka Cipta

Sudjana. (1992). Metode Statistika. Bandung: Tarsito

Walgito. (2004). Pengantar Psikologi

Umum. Yogyakarta: Andi Yogyakarta.

WHO. (1994). Contraceptive method mix. Jeneva: The World Health Organization

Widiyanti. (1987). Masalah Penduduk

Kini dan Mendatang.. Jakarta:

Pradnya Paramita 